\title{
Article \\ Magnetic Properties of FeNiCoAlTiNb Shape Memory Alloys
}

\author{
Chau-Yi Tsai ${ }^{1}$, Li-Wei Tseng ${ }^{2, *}$, Yu-Chih Tzeng ${ }^{3}{ }^{[D}$ and Po-Yu Lee ${ }^{2}$ \\ 1 Department of Materials Science and Engineering, National Formosa University, Yunlin 632301, Taiwan; \\ cytsai503@nfu.edu.tw \\ 2 Department of Mechatronics Engineering, National Changhua University of Education, \\ Changhua 50007, Taiwan; d0951003@gm.ncue.edu.tw \\ 3 Department of Power Vehicle and Systems Engineering, Chung Cheng Institute of Technology, \\ National Defense University, Taoyuan City 33550, Taiwan; s933003@ccit.ndu.edu.tw \\ * Correspondence: lwtseng@cc.ncue.edu.tw
}

Citation: Tsai, C.-Y.; Tseng, L.-W.; Tzeng, Y.-C.; Lee, P.-Y. Magnetic Properties of FeNiCoAlTiNb Shape Memory Alloys. Crystals 2022, 12, 121. https://doi.org/10.3390/ cryst12010121

Academic Editor: Luigi Manfredi

Received: 6 December 2021

Accepted: 14 January 2022

Published: 17 January 2022

Publisher's Note: MDPI stays neutral with regard to jurisdictional claims in published maps and institutional affiliations.

Copyright: () 2022 by the authors Licensee MDPI, Basel, Switzerland. This article is an open access article distributed under the terms and conditions of the Creative Commons Attribution (CC BY) license (https:// creativecommons.org/licenses/by/ $4.0 /)$.

\begin{abstract}
The magnetic properties of the new $\mathrm{Fe}_{41} \mathrm{Ni}_{28} \mathrm{Co}_{17} \mathrm{Al}_{11.5}(\mathrm{Ti}+\mathrm{Nb})_{2.5}$ (at. \%) shape memory alloy system were studied in this work. The magnetic properties were characterized by thermomagnetization and a vibrating sample magnetometer (VSM). In iron-based shape memory alloys, aging heat treatment is crucial for obtaining the properties of superelasticity and shape memory. In this study, we focus on the magnetization, martensitic transformation temperatures, and microstructure of this alloy during the aging process at $600{ }^{\circ} \mathrm{C}$. From the $\mathrm{X}$-ray diffraction (XRD) results, the new peak $\gamma^{\prime}$ is presented during the aging process. The intensity of this new peak $\left(\gamma^{\prime}\right)$ increases with the aging time, while the intensity of the FCC (111) austenite peak decreases with aging time. Transmission electron microscope (TEM) results show that the size of the precipitate increases with increasing the aging times from 24 to $72 \mathrm{~h}$. Thermo-magnetization results show that: (1) phase transformation is observed when the aging time is at least $24 \mathrm{~h},(2)$ the transformation temperature increases with the aging time, (3) transformation temperatures tend to increase while the magnetic field increases from 0.05 to 7 Tesla, and (4) the magnetization saturates after aging time reaches $24 \mathrm{~h}$. Vibrating sample magnetometer (VSM) results show that thermal process was found to significantly affect the magnetic properties of this alloy, especially on saturated magnetic magnetization and magnetic moment reversal behavior.
\end{abstract}

Keywords: shape memory alloys; FeNiCoAlTiNb; magnetic property; transformation temperatures; aging heat treatment

\section{Introduction}

Shape memory alloys (SMAs) are functional materials, and they possess two recoverable properties: the shape memory effect and superelasticity. Nickel-Titanium (NiTi) SMAs nowadays are commercial SMAs and are used in different areas of industry, such as aerospace, automotives, and robotics, due to their high recoverable strain around 7\% [1-3]. However, NiTi SMAs have a high cost in terms of material and difficulty to manufacture, which limits the application of these alloys [4]. In contrast to NiTi alloys, iron-based SMAs have a low material cost and good workability. As a result, iron-based SMAs have drawn attention and interest in both industry and academia.

FeNiCoAlXB (X: Ta, Nb, Ti) polycrystals [5-8] and single crystals [9-12] show at least $5 \%$ superelastic strain. The $\mathrm{L1}_{2}$ precipitates obtained by aging heat treatment change the materials from a non-thermo-elastic martensitic transformation to a thermo-elastic transformation [5]. The compositions of precipitates are close to (FeNiCo) 3 AlX $(X=\mathrm{Ta}, \mathrm{Nb}$, Ti). The martensitic transformation (MT) of the FeNiCoAlXB (X: Ta, Nb, Ti) alloy system is face-centered cubic (fcc) (austenite) to body-centered tetragonal (bct) (martensite).

Because the precipitates play an important role in the superelastic and shape memory properties of these alloy systems, many studies have used different aging conditions 
to obtain different size and volume fractions of precipitates to focus on the origin of thermo-elastic martensitic transformation. Geng et al. [13] carried out high-resolution transmission electron microscopy (HR-TEM) analysis of an FeNiCoAlTaB alloy in two different aging heat treatment conditions $\left(600\right.$ and $\left.700{ }^{\circ} \mathrm{C}\right)$ and observed the $\gamma^{\prime}$ precipitate containing ( $\mathrm{FeNiCo})_{3} \mathrm{AlTa}$. For aging at $600{ }^{\circ} \mathrm{C}$, the size of the precipitates slowly grows: the precipitate size is 4.7 and $5.7 \mathrm{~nm}$ for the samples aged at $600{ }^{\circ} \mathrm{C}$ for 72 and $240 \mathrm{~h}$, respectively, while for aging at $700{ }^{\circ} \mathrm{C}$, the size of the precipitates drastically increases when the aging time is longer than $24 \mathrm{~h}$. The precipitate size is $13 \mathrm{~nm}$ for $24 \mathrm{~h}$ and $40 \mathrm{~nm}$ for $240 \mathrm{~h}$. Borza et al. [14] tailored the magnetic properties of $\mathrm{FeNiCoAl}(\mathrm{Ta}, \mathrm{Nb}) \mathrm{B}$ micro-wire by controlling the percent of cold drawing. The hysteresis loop is small in as-cast wire. By increasing the percent of cold drawing to $70 \%$, the hysteresis loop increases. In the same heat treatment conditions, the saturation magnetization of FeNiCoAlTaB wire is smaller than that of FeNiCoAlNbB wire. Zhou et al. [15] investigated the effect of aging on the phase diagram and magnetic properties of FeNiCoAlTaB and NiTi alloys. Both as-cast alloys showed no phase transformation. With the increase in aging time, the martensitic transformation gradually emerged. The size and volume fraction of precipitates increased as aging time increased from 24 to $72 \mathrm{~h}$. Adarsh et al. [16] fabricated FeNiCoAlTaB alloys by two different techniques: vacuum induction melting and vacuum arc re-melting. They investigated the microstructure and magnetism of these alloys and found that the volume fraction of the $\gamma^{\prime}$ precipitates remained the same for the samples aged at $600{ }^{\circ} \mathrm{C}$ for 24 , 48 , and $72 \mathrm{~h}$, but their size increased with aging time. FeNiCoAlTaB alloys show high saturation magnetization and low coercively (Hc), as soft magnets [16].

In an FeNiCoAlTiNb alloy system, Tseng et al. [17] found that the homogeneous condition is $1277^{\circ} \mathrm{C}$ for $24 \mathrm{~h}$. When heat treatment temperature was above $1300{ }^{\circ} \mathrm{C}$, second phases were generated in the samples after being quenched with water. Poklonov et al. [18] demonstrated that FeNiCoAlTiNb single crystals with $<100>$ orientation undergo shape memory tensile tests with a $2.2 \%$ recoverable shape memory strain. The sample failed when the stress level was $150 \mathrm{MPa}$. Tseng et al. [19] investigated the shape memory properties of a cold-rolled sample by three-point bending test. The aging sample showed a $1.6 \%$ recoverable strain. In these studies, the results seldom focus on magnetic properties. Most previous research has focused mainly on the superelastic and shape memory properties, and less on the magnetic properties.

In this paper, we study the effect of aging on the microstructure and magnetic properties of the $\mathrm{Fe}_{41} \mathrm{Ni}_{28} \mathrm{Co}_{17} \mathrm{Al}_{11.5}(\mathrm{Ti}+\mathrm{Nb})_{2.5}$ (at. \%) polycrystalline alloys. The main goal is to evaluate the role of precipitate on martensitic transformation temperatures, and that of the magnetization of the aging effect on magnetic properties, composition, and microstructure. This will be useful in the fabrication of magnetic shape memory alloys.

\section{Materials and Methods}

In this study, ingots of $\mathrm{Fe}_{41} \mathrm{Ni}_{28} \mathrm{Co}_{17} \mathrm{Al}_{11.5}(\mathrm{Ti}+\mathrm{Nb})_{2.5}$ (at. \%) were prepared by Vacuum Induction Melting (VIM). The samples were heat treated in solution at $1277^{\circ} \mathrm{C}$ for $24 \mathrm{~h}(\mathrm{~h})$, followed by water quenching to homogenize the sample. The homogenous samples were then aged at $600{ }^{\circ} \mathrm{C}$ for $24,48,72$, and $96 \mathrm{~h}$ to introduce $\mathrm{L}_{2}$ precipitates $\left(\gamma^{\prime}\right)$ and water quenched (designated as $600{ }^{\circ} \mathrm{C}-24 \mathrm{~h}, 600{ }^{\circ} \mathrm{C}-48 \mathrm{~h}, 600{ }^{\circ} \mathrm{C}-72 \mathrm{~h}$, and $600{ }^{\circ} \mathrm{C}-96 \mathrm{~h}$ ). Optical microscopy $(\mathrm{OM})$ was used to observe the $\beta$ phases in different aging heat treatment conditions. Scanning electron microscopy (SEM) coupled with energy-dispersive spectrometry (EDS) was used to verify the composition of the specimens in different heat treatment stages, and the backscattered electron (BSE) image was used to determine the phases present.

The crystal structures of $1277^{\circ} \mathrm{C}-24 \mathrm{~h}$ samples aged at $600^{\circ} \mathrm{C}$ for different durations were determined using a Bruker $\mathrm{X}$-ray diffractometer (XRD) employing $\mathrm{Cu}-\mathrm{K} \alpha$ radiation at $2 \theta$ values between 30 and 60 degrees. The dimensions for all XRD test samples are $8 \mathrm{~mm} \times 8 \mathrm{~mm}$ (length $\times$ width). The size and structure of precipitate were investigated using the transmission electron microscopy (TEM). The samples aged at $600^{\circ} \mathrm{C}$ for 24,48 , and $72 \mathrm{~h}$ were prepared by focused ion beam (FIB). TEM specimens were conducted using a 
JEOL JEM-F200 electron microscope. The relationship between the magnetization and aging time was characterized by the Superconducting Quantum Interference Device (SQUID). The magnetic fields were selected at 0.05 and 7 Tesla $(\mathrm{T})$. The cooling and heating rates were decided as $5 \mathrm{~K} / \mathrm{min}$. The magnetic results were used to determine the magnetization and martensitic transformation temperatures for calculating the entropy. The experiment proceeded as follows: the sample was heated to $110^{\circ} \mathrm{C}$ under a zero magnetic field, and then cooled to $-260{ }^{\circ} \mathrm{C}$ and heated to approximately $110{ }^{\circ} \mathrm{C}$ under a constant magnetic field of 0.05 Tesla. After the test, the magnetic field became 7 Tesla. The sample was cooled from 110 to $-260{ }^{\circ} \mathrm{C}$ and heated to $110^{\circ} \mathrm{C}$ again to complete another cycle. The magnetic hysteresis loops were measured by using a vibrating sample magnetometer (VSM) with an applied field between \pm 1.5 Tesla under ambient temperature. The samples were tailored to be $0.125 \mathrm{~cm}^{3}$ cubes prior to measurement.

\section{Results and Discussion}

\subsection{Optical Microscope and EDS Results}

The optical microscope images of FeNiCoAlTiNb alloys in different aging conditions are shown in Figure 1a-f. The results show that the $\beta$ phases start to form along the grain boundaries when the aging time reaches $12 \mathrm{~h}$. $\beta$ phases first generate in the triple junction. With an increase in aging time, the $\beta$ phases increase their width and volume fraction. Because $\beta$ phases prefer to accumulate along the high-angle grain boundaries $[5,7,20]$, some grain boundaries in Figure 1 do not observe $\beta$ phases.

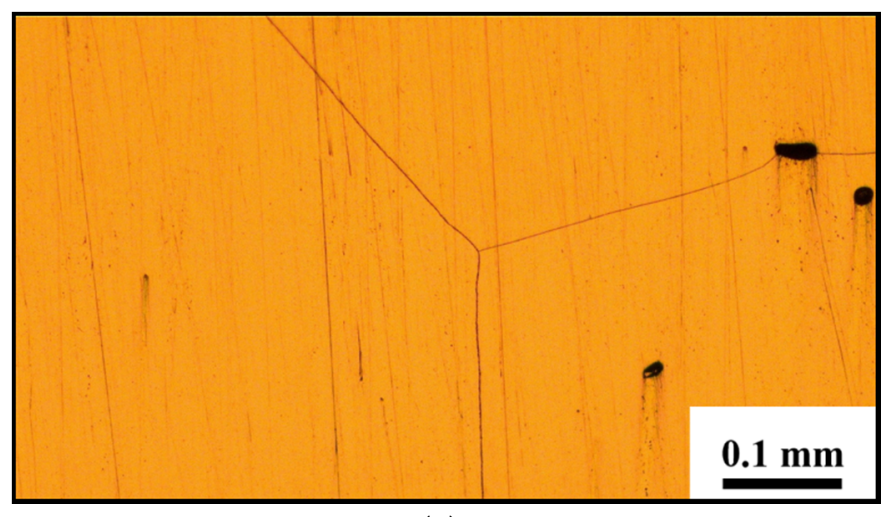

(a)

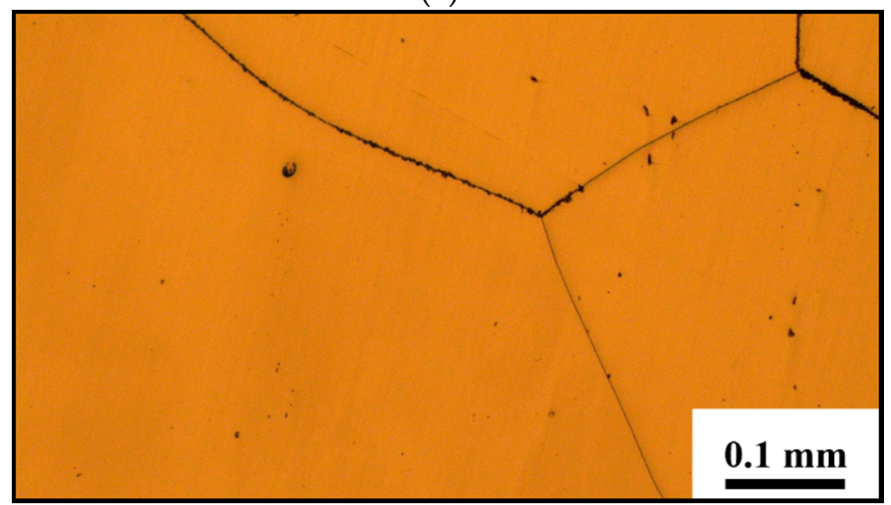

(c)

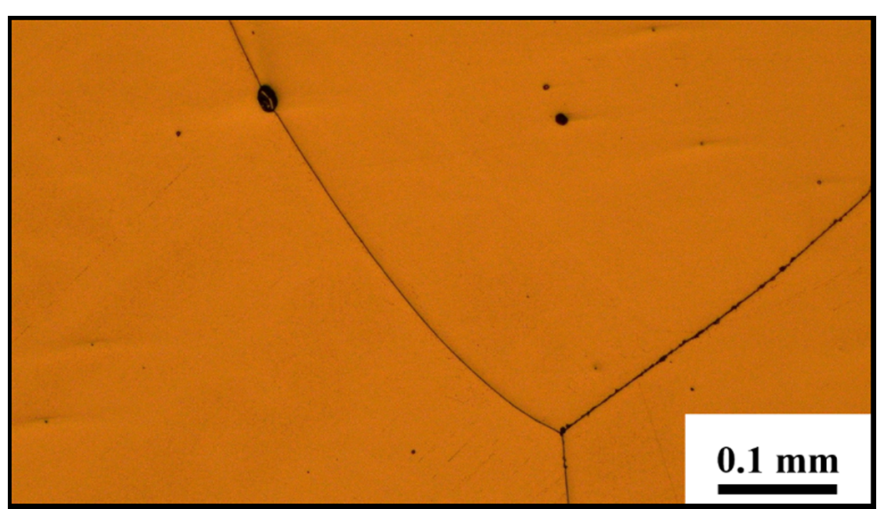

(b)

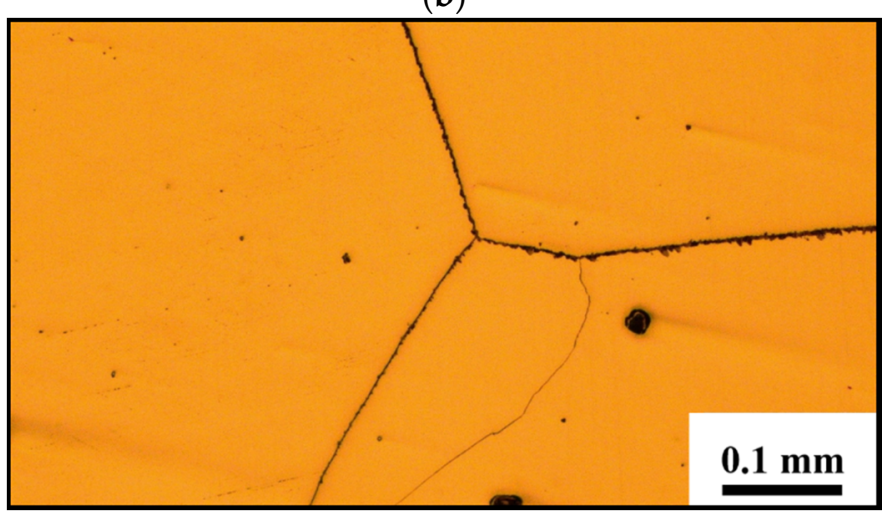

(d)

Figure 1. Cont. 


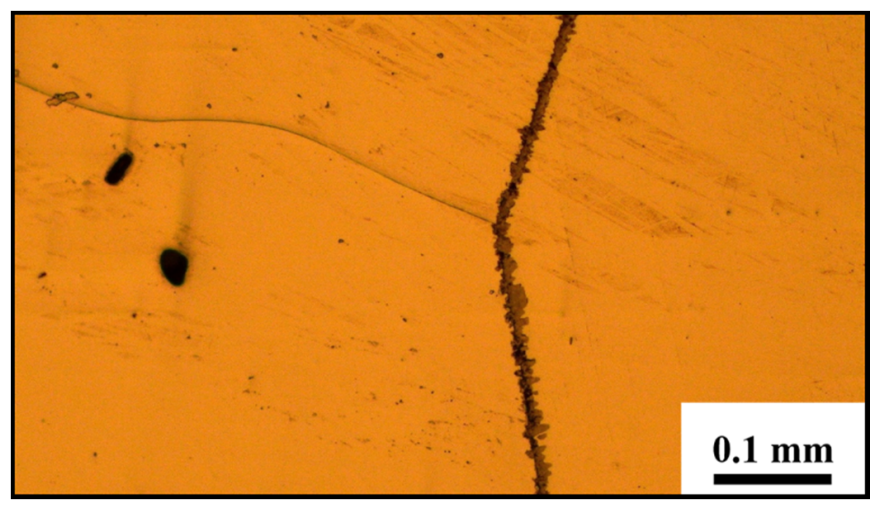

(e)

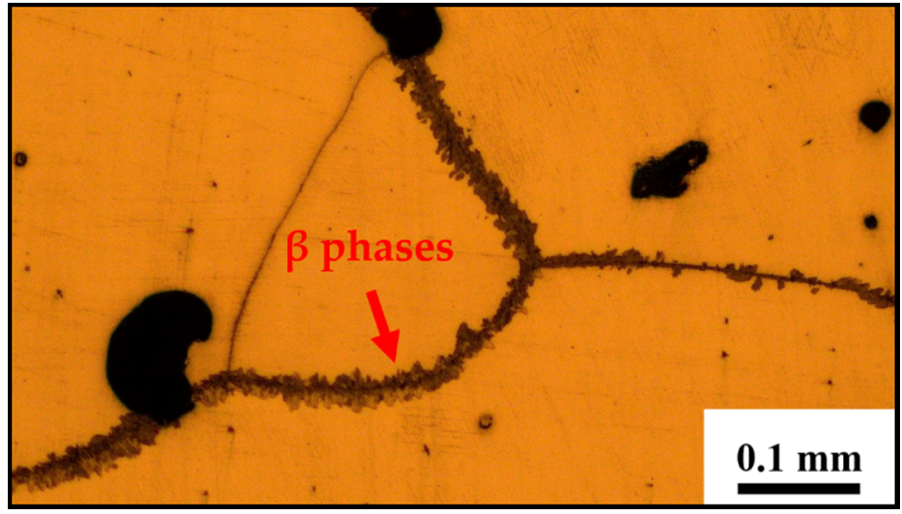

(f)

Figure 1. Optical microscope images of FeNiCoAlTiNb alloys in different aging conditions: (a) $600{ }^{\circ} \mathrm{C}-$ $10 \mathrm{~h},(\mathbf{b}) 600^{\circ} \mathrm{C}-12 \mathrm{~h},(\mathbf{c}) 600^{\circ} \mathrm{C}-24 \mathrm{~h}$ (d) $600{ }^{\circ} \mathrm{C}-48 \mathrm{~h},(\mathrm{e}) 600^{\circ} \mathrm{C}-72 \mathrm{~h}$, and (f) $600{ }^{\circ} \mathrm{C}-96 \mathrm{~h}$.

Figure 2a shows the BSE image of solution-treated polycrystalline FeNiCoAlTiNb. A large grain size is observed in this condition. Figure $2 b, c$ present the BSE image of $600{ }^{\circ} \mathrm{C}-$ $24 \mathrm{~h}$ and $600{ }^{\circ} \mathrm{C}-96 \mathrm{~h}$ samples. The numbers in the two figures indicate the EDS points. Numbers 1 and 2 are analyses in matrix and Numbers 3 and 4 are analysis in $\beta$ phases. The EDS results are summarized in Tables 1 and 2 for $600{ }^{\circ} \mathrm{C}-24 \mathrm{~h}$ and $600{ }^{\circ} \mathrm{C}-96 \mathrm{~h}$ samples. Figure $2 \mathrm{~d}$ compares the composition of solution-treated, $600{ }^{\circ} \mathrm{C}-24 \mathrm{~h}$ and $600{ }^{\circ} \mathrm{C}-96 \mathrm{~h}$ samples. The EDS results of solution-treated samples are in reference [17]. Based on the results, with an increase in aging time from 24 to $96 \mathrm{~h}$, the Ni content of the matrix decreases and the $\mathrm{Al}$ content of the matrix increases. Compared with the solution-treated sample, both the $\mathrm{Ni}$ and $\mathrm{Al}$ contents of $\beta$ phases increase as aging time increases from 24 to $96 \mathrm{~h}$.

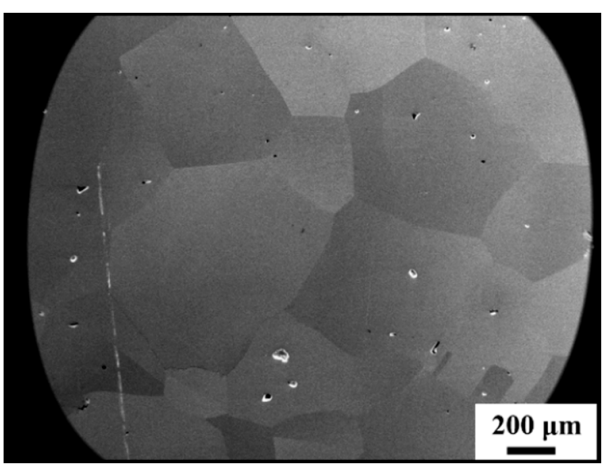

(a)

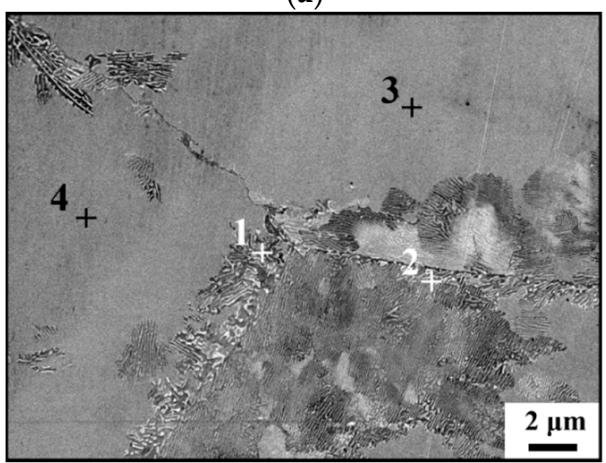

(c)

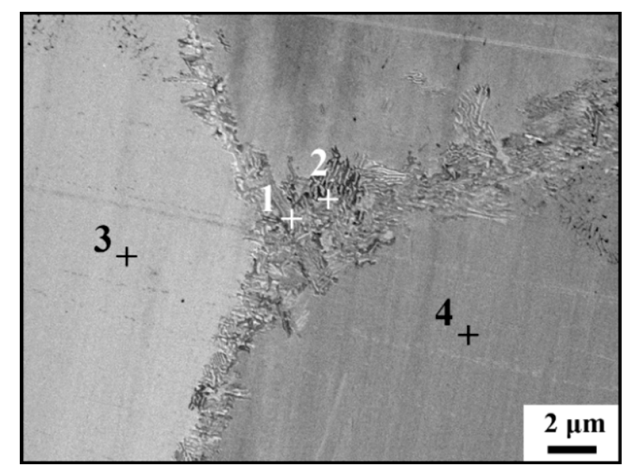

(b)

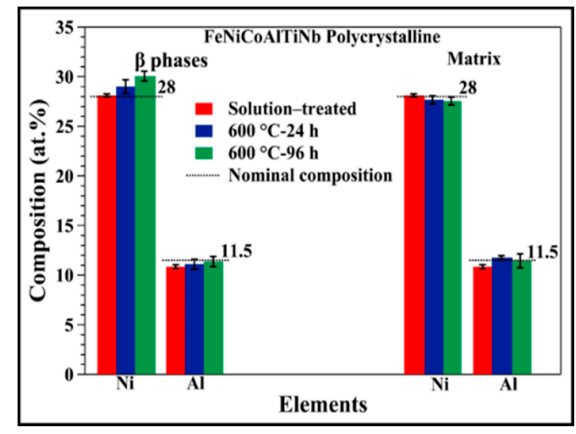

(d)

Figure 2. Backscattered electron micrograph of the FeNiCoAlTiNb polycrystalline alloy: (a) solutiontreated sample, (b) $600{ }^{\circ} \mathrm{C}-24 \mathrm{~h},(\mathrm{c}) 600^{\circ} \mathrm{C}-96 \mathrm{~h}$, and (d) comparison of composition analysis results of matrix and $\beta$ phases based on Tables 1 and 2. EDS average analysis results. 
Table 1. The composition measurements of the FeNiCoAlTiNb alloy after $600{ }^{\circ} \mathrm{C}-24 \mathrm{~h}$.

\begin{tabular}{ccccccc}
\hline & \multicolumn{3}{c}{$\boldsymbol{\beta}$ Phases } & \multicolumn{3}{c}{ Matrix } \\
\cline { 2 - 7 } Element & $\mathbf{1}$ & $\mathbf{2}$ & Average & $\mathbf{3}$ & $\mathbf{4}$ & Average \\
\hline $\mathrm{Al}(\mathrm{at} \%)$ & 10.6 & 11.6 & $11^{*} \pm 0.7$ & 12 & 11.7 & $11.76^{*} \pm 0.2$ \\
$\mathrm{Ti}(\mathrm{at} \%)$ & 0.94 & 1.72 & $1.43^{*} \pm 0.5$ & 1.49 & 1.23 & $1.25^{*} \pm 0.2$ \\
$\mathrm{Fe}(\mathrm{at} \%)$ & 40.3 & 40.6 & $40.6^{*} \pm 0.2$ & 40.2 & 39.9 & $40.25^{*} \pm 0.4$ \\
$\mathrm{Co}(\mathrm{at} \%)$ & 16.8 & 15.9 & $16.18^{*} \pm 0.6$ & 17 & 17.8 & $17.64^{*} \pm 0.6$ \\
$\mathrm{Ni}(\mathrm{at} \%)$ & 29.9 & 28.5 & $29.2^{*} \pm 0.7$ & 27.8 & 27.6 & $27.51^{*} \pm 0.3$ \\
$\mathrm{Nb}(\mathrm{at} \%)$ & 1.43 & 1.7 & $1.59^{*} \pm 0.2$ & 1.61 & 1.72 & $1.59^{*} \pm 0.1$ \\
\hline
\end{tabular}

* The standard deviations were calculated from 4 overall measurement points (here, we show two of them in Figure $2 b$.

Table 2. The composition measurements of the FeNiCoAlTiNb alloy after $600{ }^{\circ} \mathrm{C}-96 \mathrm{~h}$.

\begin{tabular}{ccccccc}
\hline \multirow{2}{*}{ Element } & \multicolumn{3}{c}{$\boldsymbol{\beta}$ Phases } & \multicolumn{3}{c}{ Matrix } \\
\cline { 2 - 7 } & $\mathbf{1}$ & $\mathbf{2}$ & Average & $\mathbf{3}$ & $\mathbf{4}$ & Average \\
\hline $\mathrm{Al} \mathrm{(at \% )}$ & 11.7 & 11 & $11.36^{*} \pm 0.4$ & 10.7 & 12.6 & $11.44^{*} \pm 0.7$ \\
$\mathrm{Ti}(\mathrm{at} \%)$ & 1.74 & 1.23 & $1.48^{*} \pm 0.3$ & 1.5 & 1.28 & $1.27^{*} \pm 0.2$ \\
$\mathrm{Fe}(\mathrm{at} \%)$ & 38.8 & 40.2 & $39.8^{*} \pm 0.5$ & 40.3 & 42.2 & $41.33^{*} \pm 0.7$ \\
$\mathrm{Co}(\mathrm{at} \%)$ & 15.9 & 16.1 & $15.9^{*} \pm 0.6$ & 17.5 & 16.2 & $17.1^{*} \pm 0.6$ \\
$\mathrm{Ni} \mathrm{(at \% )}$ & 30.6 & 29.9 & $30.2^{*} \pm 0.4$ & 28.7 & 26.4 & $27.54^{*} \pm 0.7$ \\
$\mathrm{Nb}(\mathrm{at} \%)$ & 1.19 & 1.56 & $1.26^{*} \pm 0.4$ & 1.28 & 1.29 & $1.32^{*} \pm 0.1$ \\
\hline
\end{tabular}

* The standard deviations were calculated from 4 overall measurement points (here, we show two of them in Figure $2 b$.

\subsection{XRD Results}

Figure 3 shows the XRD results of FeNiCoAlTiNb alloys under various processing conditions. An XRD peak corresponding to FCC (111) was observed in the solution-treated sample. For aged samples, a new peak $\left(\gamma^{\prime}\right)$ with a high diffraction angle was presented. The intensity of this new peak $\left(\gamma^{\prime}\right)$ increased with aging time. At the same time, the FCC (111) peak decreased. The new peak is attributed to the precipitates (L12), whose lattice parameter was slightly smaller than that of the matrix. Similar XRD patterns were also observed in the FeNiCoAlTaB alloys [15]. The peak position at 50 degrees was identified as the FCC (200) austenite phase. The intensity of the FCC (200) becomes more obvious as increasing aging time. The result suggests the austenite phase is coherent with precipitates and results in high coherence and degree of periodicity and ordering for the $\{200\}$ planes [21]. No $\beta$-NiAl precipitate peaks were observed from the XRD pattern because the grain size was large and the formation of high- and low-angle grain boundaries was random, resulting in a limited number of $\beta$ phases.

\subsection{Transmission Electron Microscope Results}

Figure 4a shows the room temperature bright field TEM image of FeNiCoAlTiNb $600{ }^{\circ} \mathrm{C}-24 \mathrm{~h}$ aging sample. The precipitates with diameter around $3-5 \mathrm{~nm}$ are clearly visible. Figure $4 \mathrm{~b}$ shows TEM images for $600{ }^{\circ} \mathrm{C}-48 \mathrm{~h}$ sample. The size of precipitates is around 7-9 nm. Figure 4c shows the corresponding selected-area electron diffraction (SAED) pattern of austenite and precipitates. The major diffraction spots are from the austenite matrix, which is a fcc phase. The spots with yellow circle are the precipitates. The precipitates are ordered $\mathrm{L}_{2}$ structure similar to the precipitate structure observed in the FeNiCoAlTaB, FeNiCoAlTa, and FeNiCoAlTi SMAs $[5,9,10,15]$. Figure $4 \mathrm{~d}$ are the TEM image of $600{ }^{\circ} \mathrm{C}-72 \mathrm{~h}$ sample. The precipitates with diameter around $10-12 \mathrm{~nm}$. The results indicate the sizes of the precipitates increase with the increase of aging times. 


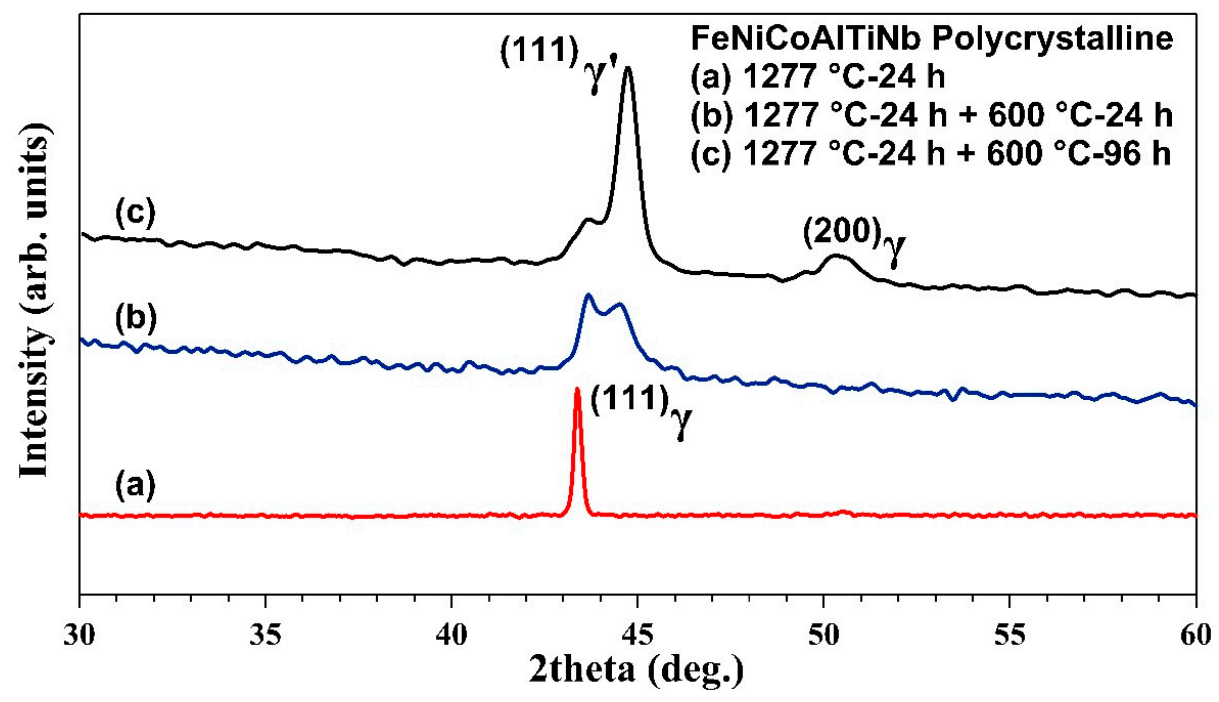

Figure 3. XRD results for FeNiCoAlTiNb alloys for different aging conditions.

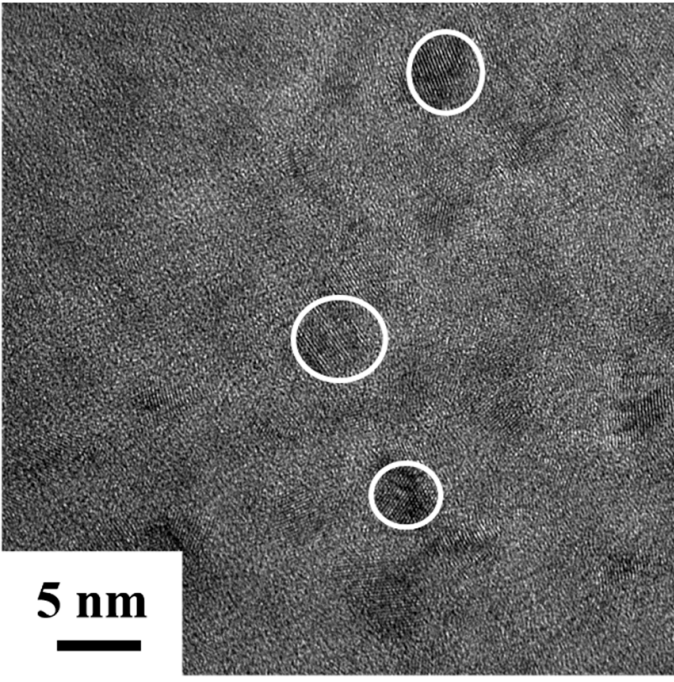

(a)

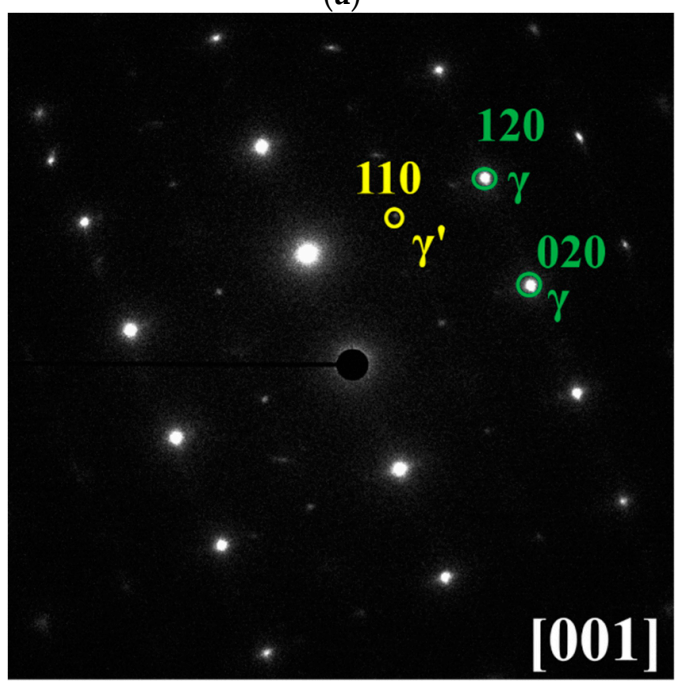

(c)

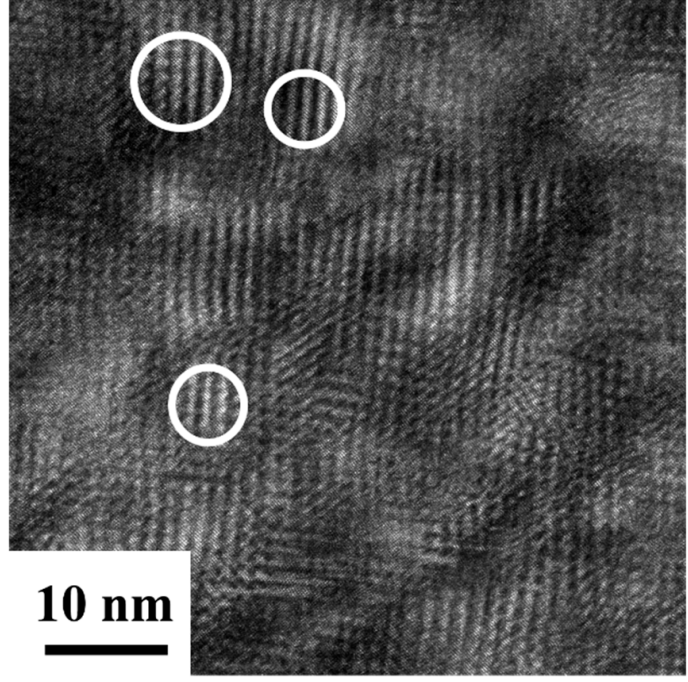

(b)

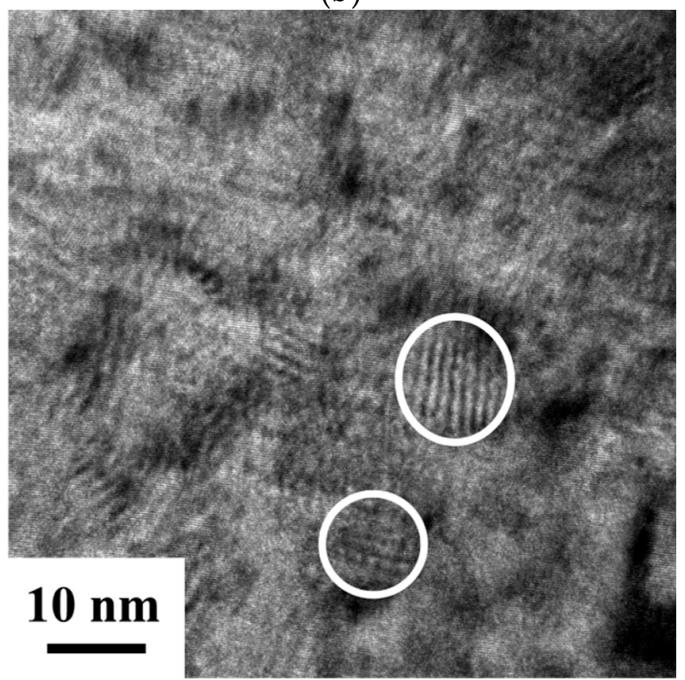

(d)

Figure 4. TEM observation of the FeNiCoAlTiNb alloys. (a) $600{ }^{\circ} \mathrm{C}-24 \mathrm{~h}$ sample, (b) $600{ }^{\circ} \mathrm{C}-48 \mathrm{~h}$ sample (c) the corresponding selected-area electron diffraction pattern, and (d) $600{ }^{\circ} \mathrm{C}-72 \mathrm{~h}$ sample. 


\subsection{Magnetization Results}

The martensitic transformation was not observed in the solution-treated sample. During the aging process, the phase transformation was not observed in the $600{ }^{\circ} \mathrm{C}-12 \mathrm{~h}$ sample, as shown in Figure 5a. Samples after aging at $600{ }^{\circ} \mathrm{C}$ for 24, 48, 72, and $96 \mathrm{~h}$ showed the phase transformation. Figure $5 \mathrm{~b}-\mathrm{e}$ displays the thermo-magnetization results of FeNiCoAlTiNb aging heat treatment at $600{ }^{\circ} \mathrm{C}$ for $24,48,72$, and $96 \mathrm{~h}$ under magnetic fields of 0.05 and $7 \mathrm{~T}$. The martensitic transformation temperatures of the aged sample can be determined by the tangent line method under $0.05 \mathrm{~T}$, as shown in Figure $5 \mathrm{~b}$. The transformation temperatures for the $600{ }^{\circ} \mathrm{C}-24 \mathrm{~h}$ sample are: austenite finish temperature $\left(\mathrm{A}_{\mathrm{f}}\right)$ $=-84{ }^{\circ} \mathrm{C}$ and martensite start temperature $\left(\mathrm{M}_{\mathrm{S}}\right)=-114^{\circ} \mathrm{C}$. The calculation of temperature hysteresis is $\Delta T_{h}=\left|A_{f}-M_{S}\right|$, and was calculated to be $30^{\circ} \mathrm{C}$. The same method was used in $600{ }^{\circ} \mathrm{C}-48 \mathrm{~h}, 600{ }^{\circ} \mathrm{C}-72 \mathrm{~h}$, and $600{ }^{\circ} \mathrm{C}-96 \mathrm{~h}$ samples. The transformation temperatures of four aging conditions under 0.05 and $7 \mathrm{~T}$ are summarized in Table 3 . Figure $5 \mathrm{f}$ summarizes the relationship between the transformation and aging times. The transformation temperatures shift to higher temperatures as aging duration increases. The transformation temperatures are related to the Ni concentration in iron-based SMAs [20]. If the Ni content is reduced, its content and the transformation temperatures tend to increase [20]. The opposite was reported for FeMnAlNi alloys [22-25], by which the transformation temperatures decreased with an increase in aging time.

Table 3. Martensitic transformation temperatures and temperature hysteresis in aged FeNiCoAlTiNb samples under 0.05 Tesla and 7 Tesla.

\begin{tabular}{ccccc}
\hline Aging Conditions & Magnetic Field (T) & $\mathbf{M}_{\mathbf{s}}\left({ }^{\circ} \mathbf{C}\right)$ & $\mathbf{A}_{\mathbf{f}}\left({ }^{\circ} \mathbf{C}\right)$ & $\begin{array}{c}\text { Temperature } \\
\text { Hysteresis }\left({ }^{\circ} \mathbf{C}\right)\end{array}$ \\
\hline \multirow{2}{*}{$600{ }^{\circ} \mathrm{C}-24 \mathrm{~h}$} & 0.05 & -114 & -84 & 30 \\
& 7 & -85 & -55 & 30 \\
$600{ }^{\circ} \mathrm{C}-48 \mathrm{~h}$ & 0.05 & -75 & -45 & 30 \\
& 7 & -57 & -27 & 30 \\
$600{ }^{\circ} \mathrm{C}-72 \mathrm{~h}$ & 0.05 & -62 & -30 & 32 \\
& 7 & -42 & -10 & 32 \\
$600{ }^{\circ} \mathrm{C}-96 \mathrm{~h}$ & 0.05 & -44 & -12 & 33 \\
& 7 & -16 & 18 & 34 \\
\hline
\end{tabular}

In a 0.05 Tesla field, the magnetization decreases during cooling and increases during the heating process. The results show that the austenite phase is ferromagnetic and martensite is weakly magnetic. When the magnetic field increases to $7 \mathrm{~T}$, the maximum magnetization level is reached for the $600{ }^{\circ} \mathrm{C}-24 \mathrm{~h}$ sample. For longer heat treatment times, the magnetization values maintain the same values. The results imply that a saturation magnetization of $140 \mathrm{emu} / \mathrm{g}$ is reached. The saturation value is higher than that of FeNiCoAlTa [9], and closer to the FeNiCoAlTaB results [5].

Moreover, the entropy can be calculated using the Clausius-Clapeyron relation in a magnetic phase diagram [21]:

$$
\Delta s \approx-\left(\frac{\Delta I}{\Delta T_{h}}\right) \Delta H
$$

where $\Delta T_{h}$ is temperature hysteresis, $\Delta H$ is magnetic field change, and $\Delta I$ is the magnetization. For the $600{ }^{\circ} \mathrm{C}-24 \mathrm{~h}$ sample, when $\Delta H$ is $7 \mathrm{~T}$, the magnetization is assumed to be $-140 \mathrm{emu} / \mathrm{g}$ and $\Delta T$ is 30 . The $\Delta s$ is around $33 \mathrm{~J} / \mathrm{K}^{-1} \mathrm{~kg}^{-1}$. In FeNiCoAlNb single crystal studies, the stress-temperature slope $(\alpha=d \sigma / d T)$ is between 3.2 and $3.8 \mathrm{MPa} / \mathrm{K}$ [26] using the Clausius-Clapeyron relation:

$$
\frac{d \sigma}{d T_{t e m}}=-\frac{\Delta s}{\varepsilon}=\alpha
$$


where $\sigma$ is the critical stress for stress-induced martensitic transformation, $T_{\text {tem }}$ is the temperature, $\alpha$ denotes the slope of the critical stress-temperature curve, $\Delta s$ is the entropy, and $\varepsilon$ is the transformation strain, which is $8.7 \%$ for theoretical transformation strain [5]. The entropy was calculated to be approximately $3.8 \times 8.7 \%=33.06 \mathrm{~J} / \mathrm{K}^{-1} \mathrm{~kg}^{-1}$ [26], which is a result similar to that of the present work. The Gibbs energy $(\Delta G)$, the driving force for the martensitic transformation, is given by $\Delta G \approx \Delta s \cdot \Delta T_{h}$. The small entropy results in the small thermal hysteresis in the martensitic transformation.

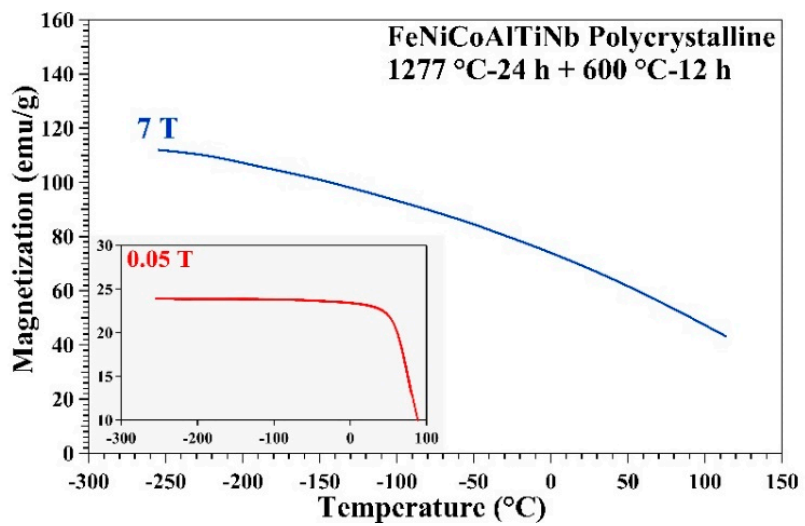

(a)

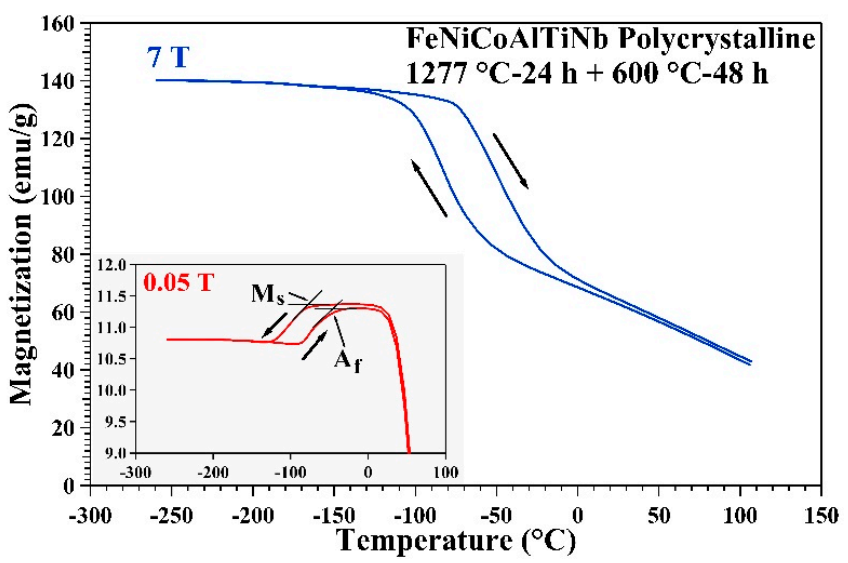

(c)

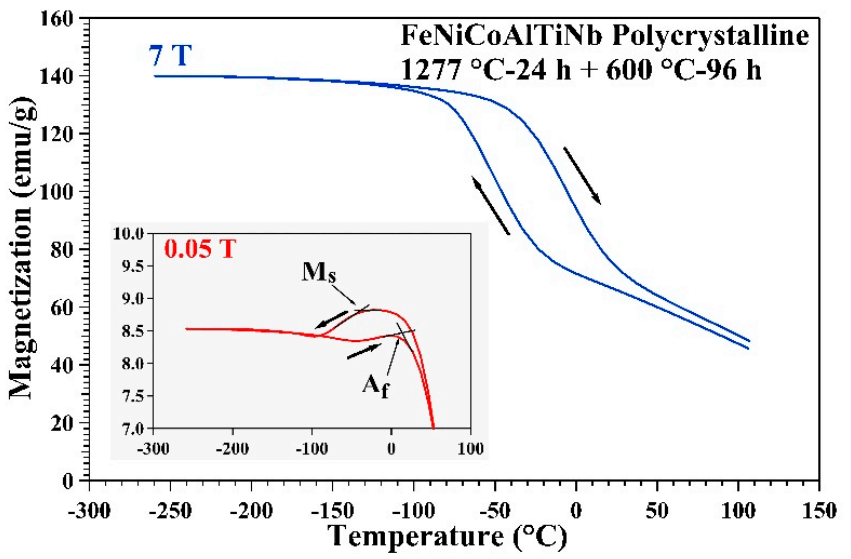

(e)

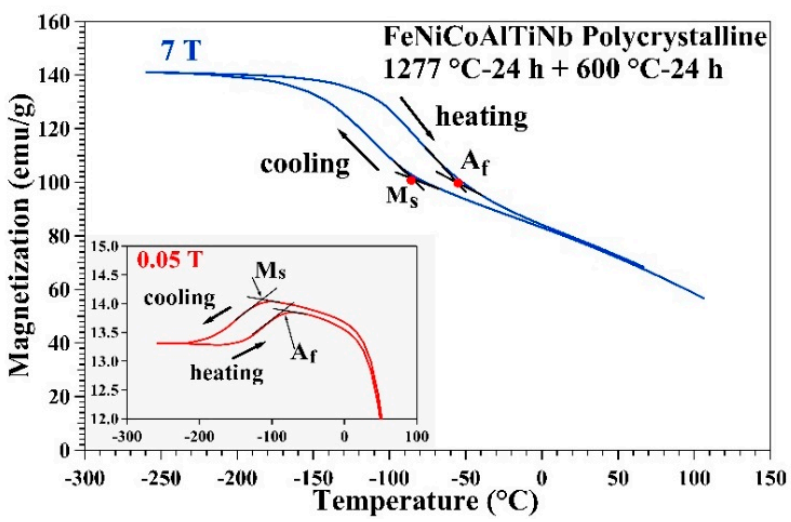

(b)

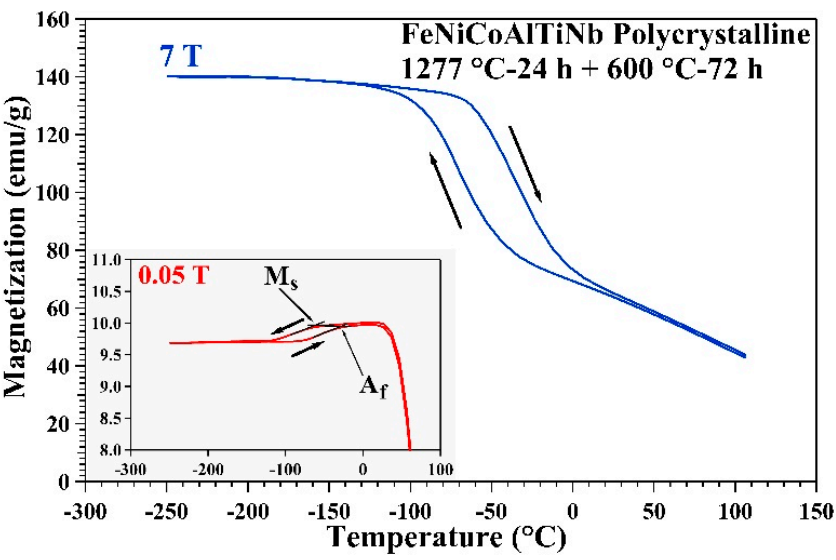

(d)

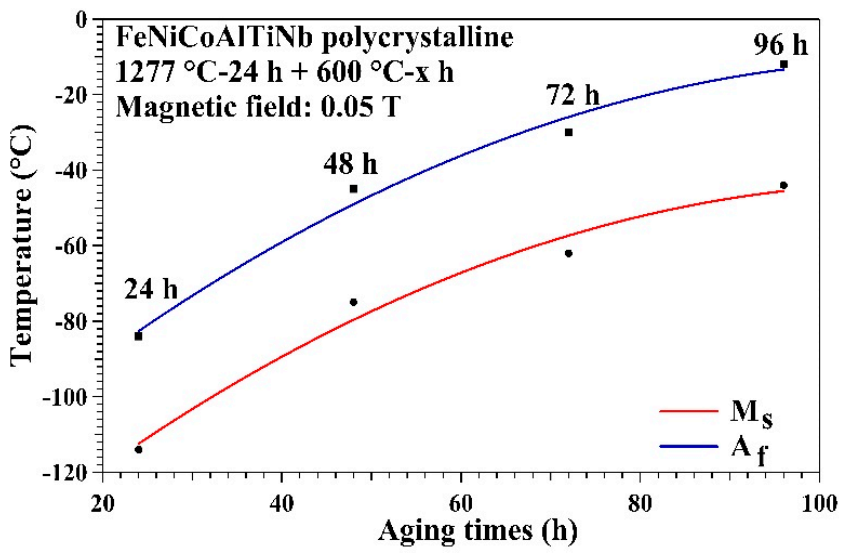

(f)

Figure 5. Thermo-magnetization curves of FeNiCoAlTiNb alloys under different aging conditions in magnetic fields of 0.05 and $7 \mathrm{~T}$ : (a) $1277^{\circ} \mathrm{C}-24 \mathrm{~h}+600^{\circ} \mathrm{C}-12 \mathrm{~h}$, (b) $1277^{\circ} \mathrm{C}-24 \mathrm{~h}+600{ }^{\circ} \mathrm{C}-24 \mathrm{~h}$, (c) $1277^{\circ} \mathrm{C}-24 \mathrm{~h}+600^{\circ} \mathrm{C}-48 \mathrm{~h},(\mathrm{~d}) 1277^{\circ} \mathrm{C}-24 \mathrm{~h}+600^{\circ} \mathrm{C}-72 \mathrm{~h},(\mathrm{e}) 1277^{\circ} \mathrm{C}-24 \mathrm{~h}+600{ }^{\circ} \mathrm{C}-96 \mathrm{~h}$, and (f) the relationship between the transformation temperature and aging time. 


\subsection{Vibrating-Sample Magnetometer Results}

Figure 6 shows the hysteresis loops of FeNiCoAlTiNb samples with different aging conditions. All samples exhibited magnetism; however, the specifics of the magnetic behaviors were found to be different among them. For the as-prepared sample, the saturated magnetization was observed as $57 \mathrm{emu} / \mathrm{g}$, as shown in Figure 6a. In addition, the magnetization decreased gradually with a smaller applied field, which suggests the magnetic moments were reversed incoherently throughout the sample. In the case of the solution-treated sample, as shown in Figure $6 \mathrm{~b}$, the saturated magnetization was measured to be $70 \mathrm{emu} / \mathrm{g}$ and the value was observed to be maintained when the applied field was higher than $0.3 \mathrm{~T}$ for both directions, and then rapidly decreased when applying a smaller field. This result reveals a relatively coherent reversal behavior of the sample. Both the high saturated magnetization value and the relatively coherent reversal of magnetic moments could be ascribed to the homogeneity of grain size and composition distribution after solution treatment. Before treatment, some magnetic moments inside the sample may be trapped by defects among scattered grains with a variety of sizes and impurities caused by composition inhomogeneity. In other words, larger grains with a similar size provide a greater volume of long-range-ordered atomic arrangement, along with well-distributed elements for the release of the trapped magnetic moments; hence, more magnetic moments could be aligned to the direction of the applied field, i.e., higher magnetization value. In addition, when free from trapping, the magnetic moments are flipped more easily, and therefore exhibit relatively coherent reversal behavior throughout the sample. Figure $6 c-g$ show samples with a variety of aging processes; the saturated magnetization for all samples could be observed to decrease to a value of approximately $30 \mathrm{emu} / \mathrm{g}$, which may be attributed to the drastic evolution of new phases to reach the shape memory transformation point of the FeNiCoAlTiNb alloy. During the process, some constituents that contribute to magnetism may reform to constituents without magnetism. In addition, two observations among these aging samples are worth mentioning. First, the reversal of magnetic moments in the sample aged for 12 and $24 \mathrm{~h}$ are slightly more incoherent than in the other three samples. When aged for $24 \mathrm{~h}$, magnetic reversal starts earlier, from $0.28 \mathrm{~T}$, and more slowly drops to the origin. On the other hand, the magnetic reversal of the other three samples all start later, from $0.24 \mathrm{~T}$, and drop to the origin point faster, i.e., more coherent reversal. This result suggests that a major shape memory transformation had already occurred when aging for $24 \mathrm{~h}$; however, the complete transformation point should be between 24 and $48 \mathrm{~h}$ of aging. This result is consistent with previous research of a similar alloy system [15]. Second, the saturated magnetization values were found to slightly decrease from $34 \mathrm{emu} / \mathrm{g}$ for aging $12 \mathrm{~h}$ to $33 \mathrm{emu} / \mathrm{g}$ for the aging 24 and $48 \mathrm{~h}$ samples, then to $31 \mathrm{emu} / \mathrm{g}$ (for aging $72 \mathrm{~h}$ ), and finally $30 \mathrm{emu} / \mathrm{g}$ (for aging $96 \mathrm{~h}$ ). The results imply that even after the complete transformation of the shape memory performance aspect, the gradual transformation of the residual constituent is still present while prolonging the aging process. However, the detailed transformation mechanism of the FeNiCoAlTiNb alloy system still requires more comprehensive studies to be completely defined. This study reveals the magnetic properties of the new shape memory alloy system, FeNiCoAlTiNb, and the results could provide a deeper understanding of the new system and other similar alloys. 


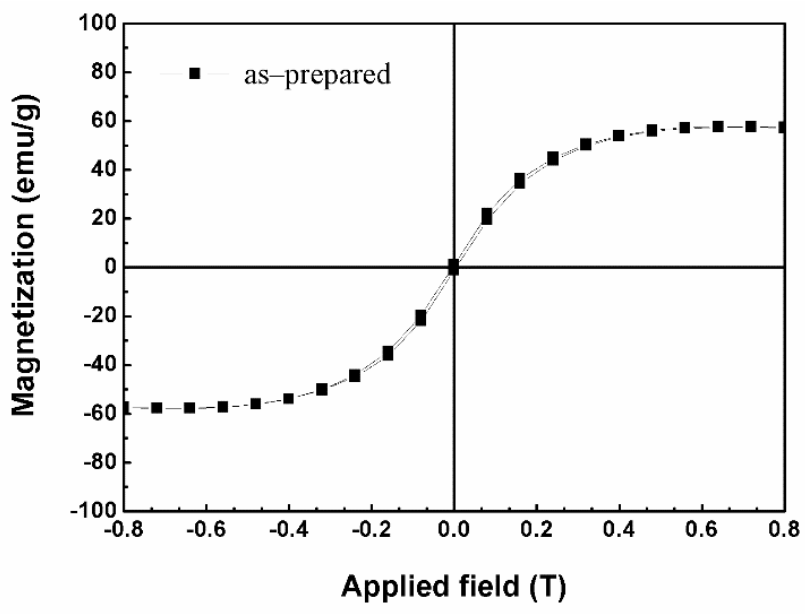

(a)

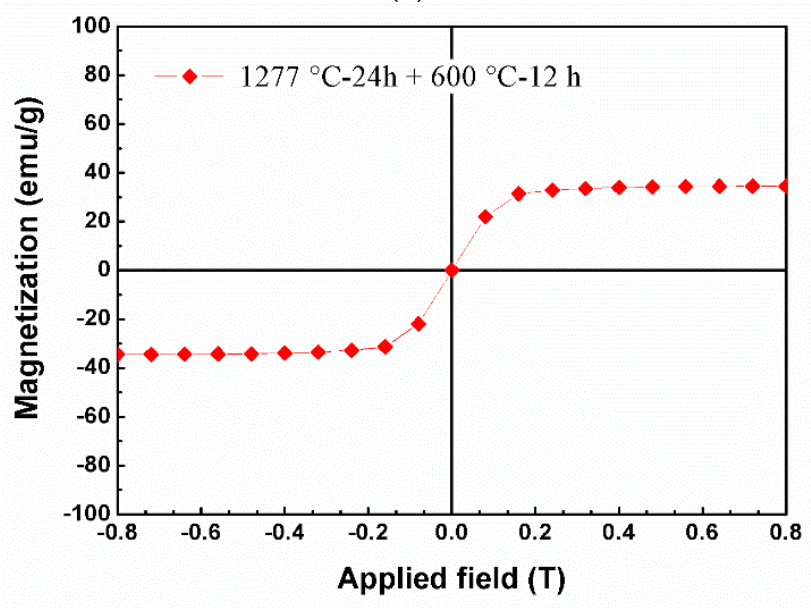

(c)

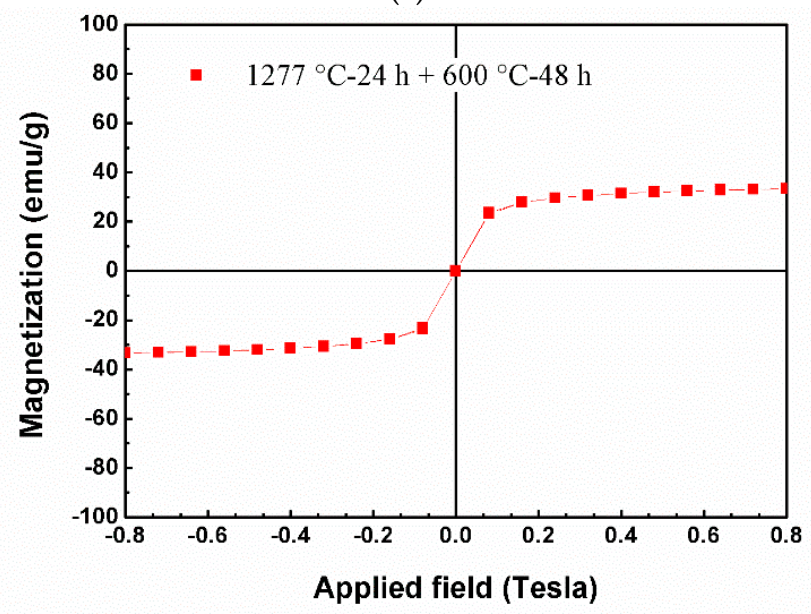

(e)

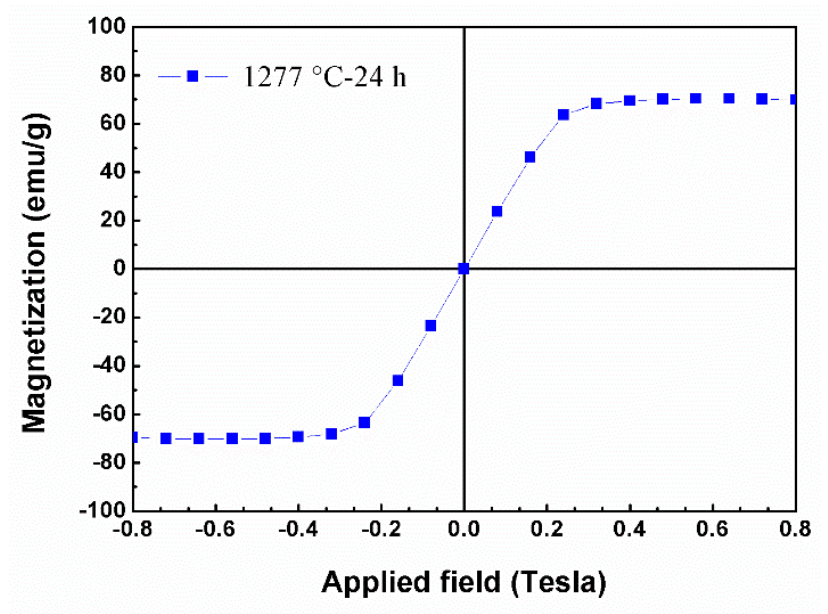

(b)

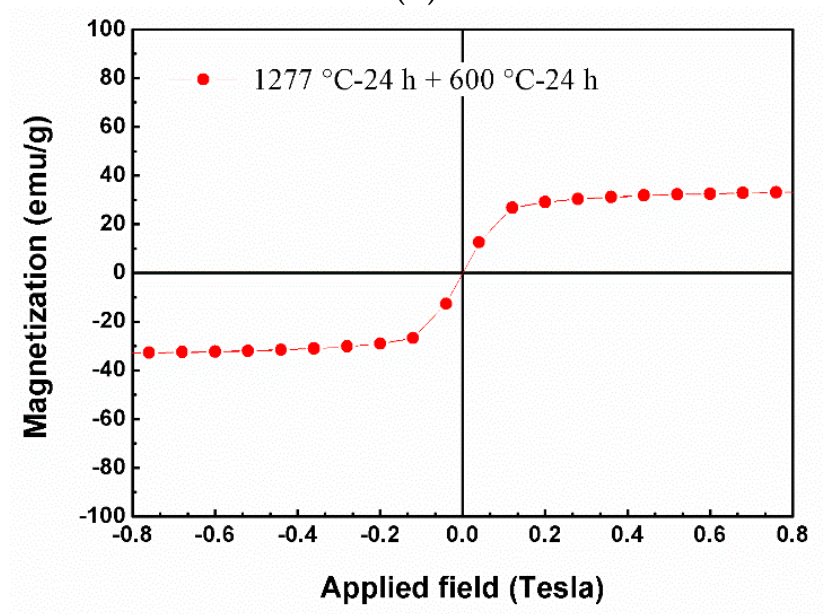

(d)

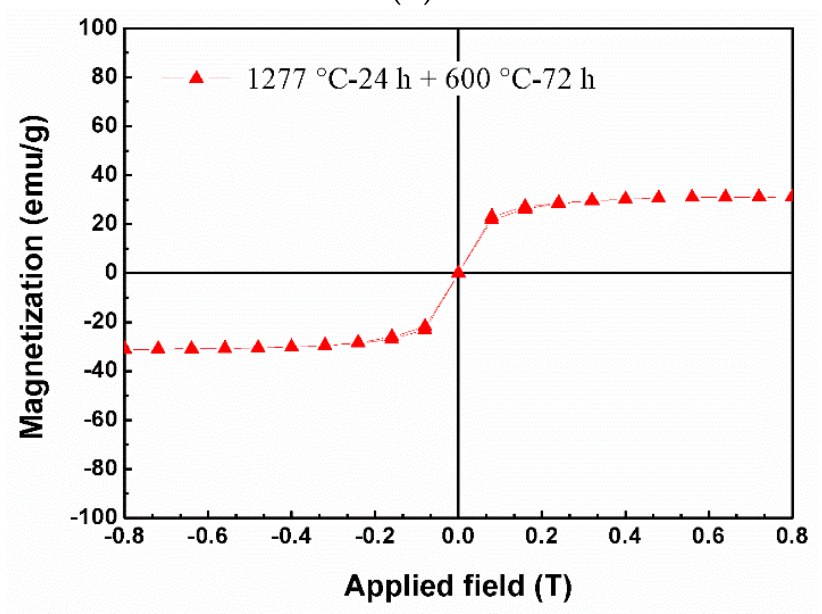

(f)

Figure 6. Cont. 


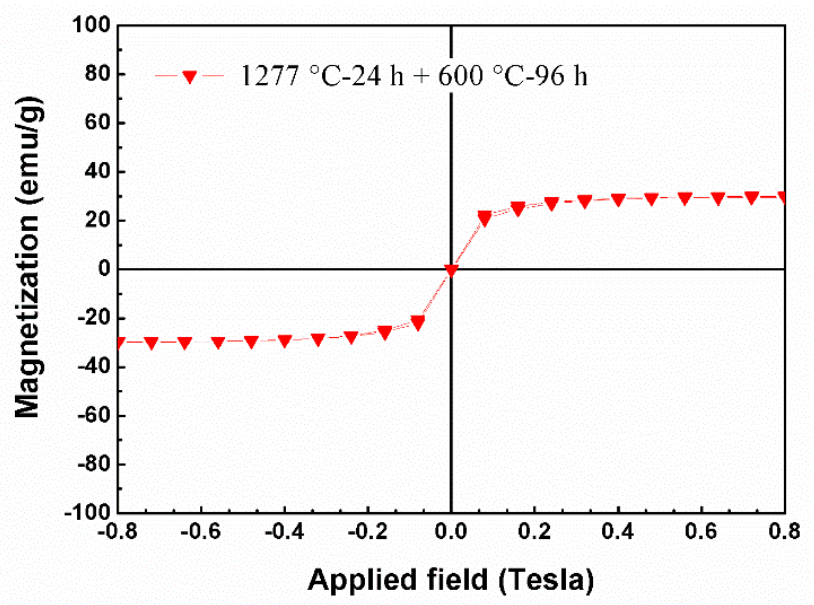

(g)

Figure 6. Hysteresis loop of FeNiCoAlTiNb samples with different aging conditions: (a) As-prepared samples, (b) $1277^{\circ} \mathrm{C}-24 \mathrm{~h}$, (c) $1277^{\circ} \mathrm{C}-24 \mathrm{~h}+600^{\circ} \mathrm{C}-12 \mathrm{~h}$, (d) $1277^{\circ} \mathrm{C}-24 \mathrm{~h}+600^{\circ} \mathrm{C}-24 \mathrm{~h},(\mathrm{e})$ $1277^{\circ} \mathrm{C}-24 \mathrm{~h}+600^{\circ} \mathrm{C}-48 \mathrm{~h},\left(\right.$ f) $1277^{\circ} \mathrm{C}-24 \mathrm{~h}+600^{\circ} \mathrm{C}-72 \mathrm{~h}$, and (g) $1277^{\circ} \mathrm{C}-24 \mathrm{~h}+600^{\circ} \mathrm{C}-96 \mathrm{~h}$.

\section{Conclusions}

In summary, the magnetic properties were investigated for FeNiCoAlTiNb SMAs for different aging times. The main conclusions can be listed as follows:

1. The XRD results show that the new peak $\gamma^{\prime}$ appears during the aging process. The intensity of this new peak $\left(\gamma^{\prime}\right)$ increases with the aging time, while the intensity of the FCC (111) austenite peak decreases with aging time.

2. The TEM results show that aging for $24 \mathrm{~h}$, only small amounts of precipitates with the size of $4-5 \mathrm{~nm}$ are obtained. When the aging time is prolonged to $48 \mathrm{~h}$, the precipitate phases grow to the size of 7-9 nm. When the aging time increases to $72 \mathrm{~h}$, the precipitates further grow up and the size of the precipitate is about 10-12 nm and the distribution of precipitates also tends to be more intensive.

3. The thermo-magnetization results show that phase transformation is observed when the aging time reaches $24 \mathrm{~h}$. The transformation temperatures increase with both aging time and magnetic field. The magnetization saturates at $140 \mathrm{emu} / \mathrm{g}$ when the aging time is $24 \mathrm{~h}$.

4. $\quad \beta$ phases prefer to be precipitated at the triple junction. Compared with the nominal composition, $\beta$ phases are enriched in $\mathrm{Ni}$ and $\mathrm{Al}$ contents. With an increase in the aging heat treatment conditions from 24 to $96 \mathrm{~h}, \mathrm{Ni}$ and $\mathrm{Al}$ contents increase.

5. From hysteresis loop studies, the thermal process was found to significantly affect the magnetic properties of this alloy. A higher saturated magnetization value $(70 \mathrm{emu} / \mathrm{g})$ and more coherent magnetic moment reversal were revealed after solution heat treatment $(57 \mathrm{emu} / \mathrm{g})$. After aging for variety of lengths of time, all samples display similar saturated magnetization $(\sim 30 \mathrm{emu} / \mathrm{g})$, which reveals that some constituents contributing to magnetism may reform to constituents without magnetism. By considering reversal behavior, the complete transformation point of the shape memory feature lies between 24 and $48 \mathrm{~h}$ of aging. The gradually reduced saturated magnetization values imply that residual constituent transformation was still present when prolonging aging time. These results regarding magnetic properties could provide a deeper understanding of the new system and other similar alloys. 


\begin{abstract}
Author Contributions: Conceptualization, L.-W.T.; methodology, L.-W.T. and C.-Y.T.; validation, L.-W.T. and C.-Y.T.; investigation, L.-W.T., Y.-C.T., P.-Y.L. and C.-Y.T.; resources, L.-W.T.; data curation, P.-Y.L. and C.-Y.T.; writing-original draft preparation, C.-Y.T. and L.-W.T.; writing—review and editing, L.-W.T.; visualization, C.-Y.T. and L.-W.T.; supervision, L.-W.T.; project administration, L.-W.T. All authors have read and agreed to the published version of the manuscript.
\end{abstract}

Funding: This research was funded by the Ministry of Science and Technology (MOST), grant number MOST 109-2221-E-018-010-MY2.

Acknowledgments: The FeNiCoAlTiNb alloys were fabricated by the National Chung-Shan Institute of Science and Technology (NCSIST), which is gratefully acknowledged. The authors would like to thank Yung-Sheng Chen at Instrumentation Center, National Tsing Hua University for SQUID measurements.

Conflicts of Interest: The authors declare no conflict of interest.

\title{
References
}

1. Otsuka, K.; Wayman, C.M. Shape Memory Materials; Cambridge University Press: Cambridge, UK, 1998; pp. 117-132.

2. Jani, J.M.; Leary, M.; Subic, A.; Gibson, M.A. A review of shape memory alloy research, applications and opportunities. Mater. Des. 2014, 56, 1078-1113. [CrossRef]

3. Omori, T.; Kainuma, R. Martensitic transformation and superelasticity in Fe-Mn-Al-Based shape memory alloys. Shape Mem. Superelasticity 2017, 3, 322-334. [CrossRef]

4. Khalil, W.; Mikolajczak, A.; Bouby, C.; Zineb, T.B. A constitutive model for Fe-based shape memory alloy considering martensitic transformation and plastic sliding coupling: Application to a finite element structural analysis. J. Intell. Mater. Syst. Struct. 2012, 23, 1143-1160. [CrossRef]

5. Tanaka, Y.; Himuro, Y.; Kainuma, R.; Sutou, Y.; Omori, T.; Ishida, K. Ferrous polycrystalline shape-memory alloy showing huge superelasticity. Science 2010, 27, 1488-1490. [CrossRef]

6. Choi, W.S.; Pang, E.L.; Choi, P.P.; Schuh, C.A. FeNiCoAlTaB superelastic and shape-memory wires with oligocrystalline grain structure. Scr. Mater. 2020, 188, 1-5. [CrossRef]

7. Lee, D.; Omori, T.; Kainuma, K. Ductility enhancement and superelasticity in Fe-Ni-Co-Al-Ti-B polycrystalline alloy. J. Alloys Compd. 2014, 617, 120-123. [CrossRef]

8. Omori, T.; Abe, S.; Tanaka, Y.; Lee, D.; Ishida, K.; Kainuma, R. Thermoelastic martensitic transformation and superelasticity in Fe-Ni-Co-Al-Nb-B polycrystalline alloy. Scr. Mater. 2013, 69, 812-815. [CrossRef]

9. Ma, J.; Hornbuckle, B.; Karaman, I.; Thompson, G.B.; Luo, Z.; Chumlyakov, Y. The effect of nanoprecipitates on the superelastic properties of FeNiCoAlTa shape memory alloy single crystals. Acta Mater. 2013, 61, 3445-3455. [CrossRef]

10. Tseng, L.W.; Ma, J.; Karaman, I.; Wang, S.J.; Chumlyakov, Y. Superelastic response of the FeNiCoAlTi single crystals under tension and compression. Scr. Mater. 2015, 101, 1-4. [CrossRef]

11. Chumlyakov, Y.I.; Kireeva, I.V.; Kutz, O.A.; Turabi, A.S.; Karaca, H.E.; Karaman, I. Unusual reversible twinning modes and giant superelastic strains in FeNiCoAlNb single crystals. Scr. Mater. 2016, 119, 43-46. [CrossRef]

12. Chumlyakov, Y.I.; Kireeva, I.V.; Pobedennaya, P.; Kroo $\beta$, P.; Niendorf, T. Rubber-like behaviour and superelasticity of [001]oriented FeNiCoAlNb single crystals containing $\gamma$ - and $\beta$-phase particles. J. Alloys Compd. 2021, 856, 158158. [CrossRef]

13. Geng, Y.; Lee, D.; Xu, X.; Nagasako, M.; Jin, X.; Omori, T.; Kainuma, R. Coherency of ordered $\gamma^{\prime}$ precipitates and thermoelastic martensitic transformation in FeNiCoAlTaB alloys. J. Alloys Compd. 2015, 628, 287-292. [CrossRef]

14. Borza, F.; Lupu, N.; Dobrea, V.; Chiriac, H. Tailoring the magnetic properties of new Fe-Ni-Co-Al-(Ta,Nb)-B superelastic rapidly quenched microwires. Appl. Phys. Lett. 2015, 117, 17E512. [CrossRef]

15. Zhou, Z.; Cui, J.; Ren, X. Phase diagram of FeNiCoAlTaB ferrous shape memory alloy on aging time. AIP Adv. 2017, 7, 045019. [CrossRef]

16. Adarsh, S.H.; Sampath, V. Influence of microstructure on mechanical and magnetic properties of an Fe-Ni-Co-Al-Ta-B shape memory alloy. Mater. Res. Express 2019, 6, 075701. [CrossRef]

17. Tseng, L.W.; Tzeng, Y.C.; Tsai, Y.L.; Chumlyakov, Y.I. Microstructure investigation of new iron-based FeNiCoAlTiNb shape memory alloys. Results Mater. 2021, 10, 1001881-1001887. [CrossRef]

18. Poklonov, V.; Chumlyakov, Y.; Kireeva, I.; Lyamkind, S. Thermoelastic martensitic transformation in single crystals of FeNiCoAlTiNb alloy. AIP Conf. Proc. 2017, 1909, 020174.

19. Tseng, L.W.; Chen, C.H.; Chen, W.C.; Cheng, Y.; Lu, N.H. Shape memory properties and microstructure of new iron-based FeNiCoAlTiNb shape memory alloys. Crystals 2021, 11, 1253. [CrossRef]

20. Zhang, C.; Zhu, C.; Shin, S.; Casalena, L.; Vecchio, K. Grain boundary precipitation of tantalum and NiAl in superelastic FeNiCoAlTaB alloy. Sci. Eng. A 2019, 743, 372-381. [CrossRef]

21. Czerny, M.; Maziarz, W.; Cios, G.; Wojcik, A.; Chumlyakov, Y.I.; Schell, N.; Fitta, M.; Chulist, R. The effect of heat treatment on the precipitation hardening in FeNiCoAlTa single crystals. Mater. Sci. Eng. A 2020, 784, 139327. [CrossRef] 
22. Ando, K.; Omori, T.; Ohnuma, T.; Kainuma, R.; Ishida, K. Ferromagnetic to weak-magnetic transition accompanied by bcc to fcc transformation in Fe-Mn-Al alloy. Appl. Phys. Lett. 2009, 95, 212504. [CrossRef]

23. Tseng, L.W.; Ma, J.; Wang, S.J.; Karaman, I.; Kaya, M.; Luo, Z.P.; Chumlyakov, Y.I. Superelastic response of a single crystalline FeMnAlNi shape memory alloy under tension and compression. Acta Mater. 2015, 89, 374-383. [CrossRef]

24. Tseng, L.W.; Ma, J.; Hornbuckle, B.; Karaman, I.; Thompson, G.B.; Luo, Z.; Chumlyakov, Y. The effect of precipitates on the superelastic response of [100] oriented FeMnAlNi single crystals under compression. Acta Mater. 2015, 97, 234-244. [CrossRef]

25. Tseng, L.W.; Ma, J.; Karaman, I.; Chumlyakov, Y.I. Orientation dependence of superelasticity in FeMnAlNi single crystals under compression. Scr. Mater. 2019, 166, 48-52. [CrossRef]

26. Chumlyakov, Y.I.; Kireeva, I.V.; Pobedennaya, Z.V.; Krooß, P.; Niendorf, T. Shape memory effect and superelasticity of [001]Oriented FeNiCoAlNb single crystals aged under and without stress. Metals 2021, 11, 943. [CrossRef] 